\title{
Opioid Dependent and Pregnant: What Are the Best Options for Mothers and Neonates?
}

\author{
Annemarie Unger, Verena Metz, and Gabriele Fischer \\ Department of Psychiatry and Psychotherapy, University Hospital of Vienna, 1090 Vienna, Austria \\ Correspondence should be addressed to Gabriele Fischer, gabriele.fischer@meduniwien.ac.at \\ Received 7 September 2011; Revised 30 October 2011; Accepted 30 October 2011 \\ Academic Editor: Gideon Koren
}

Copyright ( $) 2012$ Annemarie Unger et al. This is an open access article distributed under the Creative Commons Attribution License, which permits unrestricted use, distribution, and reproduction in any medium, provided the original work is properly cited.

\begin{abstract}
Pregnancy in opioid-dependent women is a major public health issue. Women who are afflicted by opioid addiction are a highly vulnerable group of patients frequently becoming pregnant unplanned and at risk of adverse pregnancy outcomes and perinatal complications. Opioid agonist maintenance treatment is the best option for the majority of women. Ideally, early and closely monitored treatment in an interdisciplinary team approach including social workers, nurses, psychologists, psychiatrists, gynecologists, anesthesiologists, and pediatricians should be provided. The treatment of comorbid psychiatric conditions, the resolution of financial, legal, and housing issues, and the psychosocial support provided have a significant effect on optimizing pregnancy outcomes. This paper aims to update health professionals in the field of gynecology and obstetrics on the latest optimal treatment approaches for mothers suffering from opioid dependence and their neonates.
\end{abstract}

\section{Introduction}

Illicit drug use among pregnant women is an international health issue that has become of increasing relevance in the past decades. In 2001, a national household survey reported $3.7 \%$ of pregnant women in the United States using illicit drugs [1]. In 2009 this number had increased to $4.5 \%$ [2]. The actual numbers are higher if estimated numbers of unreported cases are taken into account due to fear of stigmatism impairing self-report measures. In fact, a study of maternal urine samples at delivery of 715 women in Florida showed $13.3 \%$ were positive for an illicit drug such as marijuana, cocaine, or opiates. Although among illicit substances, the prevalence of substance abuse among pregnant women was highest for marijuana, followed by cocaine [3], the prevalence of opioid dependence was on the rise between 1970 and 1980 [4] and an estimated 8 million people worldwide were reported to abuse opioids in 2003 [5]. Though men still outnumber women, the proportion of women continues to increase, and more than $70 \%$ of opioid-dependent women are of child-bearing age. Unplanned pregnancies are common due to effects of opioids on the female reproductive system, frequently leading to irregular menstruation or amenorrhea [6]. Additionally, chaotic lifestyles associated with drug abuse often foster insufficient birth control measures and consequently unexpected pregnancies. In fact, the rate of unintended pregnancies has been found to range between $80 \%$ and $90 \%$ among opioid-dependent women [7].

\section{Opioid Dependence and Pregnancy}

Opioid-dependent women commonly face numerous socioeconomic problems such as unemployment, coaddicted partners, and partner violence [8]. Prostitution as a means of attaining drugs often leads to health problems such as infectious disease or these occur as a consequence of syringe sharing and are poorly attended to [9]. The majority of opioid-dependent women suffer cooccurring psychiatric disorders with prevalence numbers ranging between 56 and $73 \%$, mainly affective disorders, PTSD, or personality disorders [9-11] (see Table 1).

The failure to recognize mental disorders is a major risk to the health of mother and neonate as comorbid depression, anxiety disorders, and psychosis are associated with a variety 
TABLE 1: Psychiatric comorbidity in substance abuse treatment and matched controls*.

\begin{tabular}{lcc}
\hline & SA & Controls \\
\hline Depression & $36.3 \%$ & $4.2 \%$ \\
Anxiety disorder & $16.3 \%$ & $2.3 \%$ \\
ADHD & $17.2 \%$ & $3.0 \%$ \\
Conduct disorder & $19.3 \%$ & $1.2 \%$ \\
Conduct disorder (w/ODD) & $27.3 \%$ & $2.3 \%$ \\
Any psychiatric diagnosis & $55.5 \%$ & $9.0 \%$ \\
\hline
\end{tabular}

* All $P<.001$ [12].

of negative pregnancy outcomes [13]. Examples of these are preterm labor and poor fetal growth [14, 15], a heightened risk for perinatal complications and dysfunctional motherchild bonding [16]. Ideally, comorbid psychiatric conditions should be adequately treated, and the use of antidepressant drugs such as SSRI medication, which has been shown to be safe during pregnancy, may be indicated. However, a careful risk-benefit evaluation of pharmacological treatment by a psychiatric professional experienced in treating pregnant women is warranted [17]. It should be part of a multiprofessional team approach comprising psychiatrists, psychologists, gynecologists, midwifes, nurses, social workers, and anesthesiologists. (see Figure 1).

\section{Medical Treatment of Opioid-Dependent Pregnant Women}

Though ultimately, abstinence from opioids might seem the best option during pregnancy, few opioid-addicted women can handle abstaining from opioids at such a time in their lives filled with changes and stress. Additionally, rapid detoxification during pregnancy cannot be recommended from a medical standpoint, as withdrawal has been linked to intrauterine stress for the fetus associated with poor fetal growth, preterm delivery, and fetal death [18]. Though gradual detoxification in the second or third trimesters has been achieved in a selected group of women, the majority of women have a high risk of relapse. The best option for most opioid-addicted pregnant women is opioid maintenance treatment with a long-acting synthetic opioid such as methadone or buprenorphine [19-24]. Methadone has for a long time been the established maintenance medication for pregnancy $[25,26]$, however, in recent years, buprenorphine has been increasingly subject of studies as a valuable alternative to methadone with beneficial effects on the neonatal abstinence syndrome of the newborn.

Pioneer work with standardized prospective evaluation on the use of buprenorphine in pregnant women has been conducted in the late 1990s by Fischer et al. at the Addiction Clinic in Vienna, who was first to publish a study demonstrating maternal and fetal safety of women maintained on buprenorphine during pregnancy and consecutively during conception [22, 27]. The pilot study published in 2000 was followed by a double-blind, double dummy comparison study of 14 women published in 2006, forming a first basis for larger follow-up studies and showing higher retention rates in the buprenorphine group. So far, the largest double-blind, double dummy study comparing the safety and efficacy of buprenorphine versus methadone in pregnant opioid-dependent women was the "MOTHER study" (Maternal Opioid Treatment: Human Experimental Research). It was conducted between 2005 and 2008 as a multisite randomized controlled trial encompassing 6 US American sites and one European site at the Addiction Clinic, University Hospital of Vienna, Austria. The main outcome of this trial of 131 completers and their neonates was recently published in the New England Journal of Medicine [28], finding that neonates prenatally exposed to buprenorphine had a significantly shorter duration of treatment and required significantly lower amounts of morphine medication compared to methadoneexposed neonates. The shorter duration of hospitalization of buprenorphine-exposed neonates should also be seen in the light of health service costs, as large numbers of neonates are affected by NAS every year. However, treatment with methadone still has its place as 28 of 86 women in the buprenorphine group (33\%) discontinued treatment compared to 16 of 89 women (18\%) maintained on methadone [28]. Buprenorphine can be seen as an important treatment option for this target group, but methadone continues to be the medication for those women who do not positively respond to buprenorphine.

Another important aspect affecting pregnant opioidmaintained women that deserves mention is the need for dose adjustment in the majority of women, usually around the beginning of the third trimester, due to changes in metabolic rates, increased estrogen levels, and enzyme induction [29, 30]. After delivery, most women will request dose decreases due to changes in hormonal status. The same principle applies to the use of psychotropic medications during pregnancy, such as SSRIs, where frequently dose adjustment is necessary, and psychiatric symptoms can worsen temporarily.

Recent reports have shown that not only the dose but also the duration of maintenance treatment during pregnancy plays a role in improvement of pregnancy outcomes, as in a recent study women who had been on methadone maintenance treatment (MMT) for the full pregnancy had higher birth weights and a higher likelihood of abstinence from concomitant medication associated with higher gestational age at delivery compared to women who had only been on MMT for part of their pregnancy [31]. Results from studies like this emphasize the responsibility of gynecologists to seek close cooperation with addiction specialists as soon as pregnancy is ascertained.

\section{Perinatal Pain Management of Opioid-Dependent Women}

Opioid dependence is associated with heightened sensitivity to pain, chronic hyperalgesia, and tolerance to opioid pain medication [32], making peripartum pain management of opioid-dependent women particularly challenging. There is a 


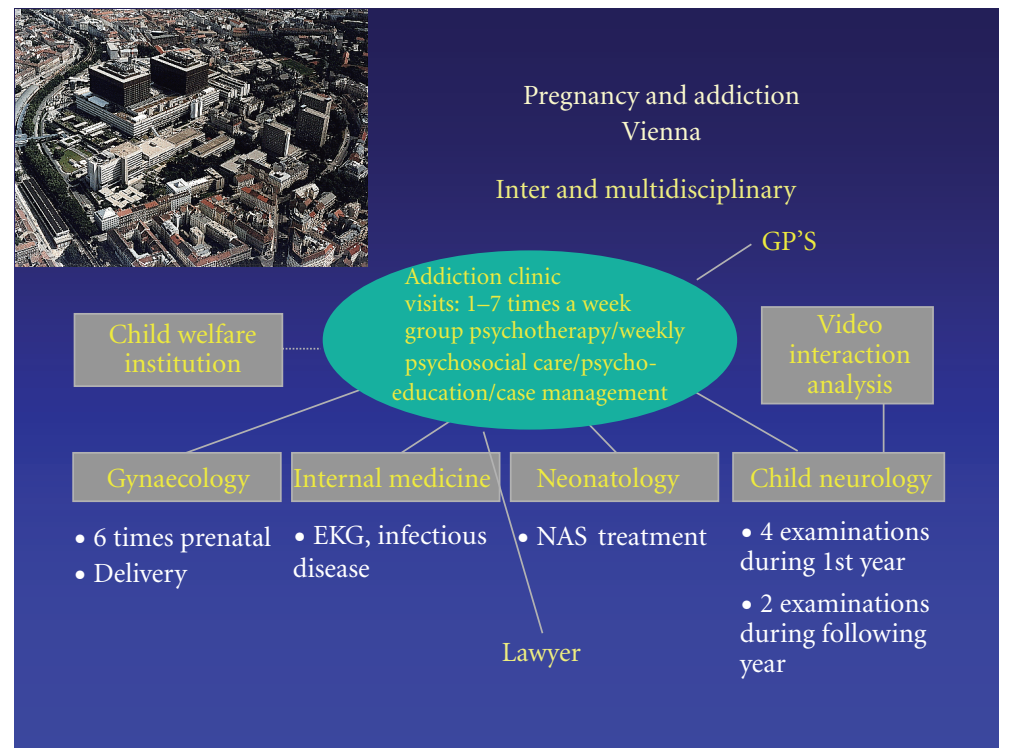

FIgURE 1: The multiprofessional team approach at the Addiction Clinic, University hospital of Vienna, Department of Psychiatry.

persistent lack of standardized treatment recommendations, stigma, and overcaution due to fear of "drug-seeking" behavior, resulting in undertreatment of peripartum pain in the majority of cases. Additional factors such as nicotine addiction also contribute to heightened pain sensitivity [33, 34]. This is significant given that more than $90 \%$ of opioiddependent women are smokers [35]. Due to abrupt nicotine deprivation in the hospital, they often require higher doses of pain medication [36]. Furthermore, the high prevalence of other psychiatric diagnoses, such as affective disorders, represent an additional independent predictor of intensified pain experience $[32,37]$. Prior recommendations on pain treatment of opioid-dependent patients have stressed the importance of continuous, adequately dosed maintenance treatment as a basis [38]. Recent findings support this recommendation and, additionally, the use of NSAIDs (NonSteroidal Anti-Inflammatory Drugs) to supplement, and the use of opioids, other than the ones used for maintenance treatment, for sufficient pain control during delivery and postpartum $[32,39]$. The use of NSAIDs cannot be recommended during pregnancy, particularly during the third trimester due to the risk of early closure of the ductus arteriosus. In early pregnancy the use of NSAIDs has been linked to increased risk of miscarriage and premature birth [40].

\section{The Neonatal Abstinence Syndrome of the Newborn}

The neonatal abstinence syndrome of the newborn is a condition which becomes manifest in the first few days after delivery affecting more than half of newborns born to opioid-dependent mothers [41]. It is characterized by symptoms affecting primarily the central nervous system, the respiratory system, and the digestive tract. The first scale for measurement of neonatal abstinence syndrome was developed by Loretta Finnegan et al. in the early 1970s [42]. It consists of symptoms such as increased sneezing, watery eyes, frequent yawning, poor sucking, reduced sleep duration after feeding, and increased (hyper) reflexes. Management of this condition is best handled in a multiprofessional team approach in specially trained centers, where symptoms of neonates are rated at regular intervals and, if needed, treatment is initiated using morphine hydrochloride drops given to infants. In 2007, Fischer and colleagues at the Vienna addiction clinic published a study comparing phenobarbital to morphine hydrochloride as NAS treatment medication, showing that the majority of neonates had a significantly shorter duration of NAS under morphine hydrochloride drops which has become the established form of treatment [43]. However, prolonged use of morphine in the postnatal period should be avoided as recent studies have demonstrated a number of negative consequences of opioids on neural cells of the growing brain [44].

A recently updated Cochrane review by Osborn referring to treatment options in 645 infants confirmed that opiate (morphine) treatment is superior to supportive care only. The analysis of prior studies also showed that opiate treatment was also superior to phenobarbitone and to diazepam in terms of rates of treatment failure and in reducing the likelihood of seizures [41]. The basis for effective medical treatment of NAS is the standardized rating of symptoms in neonates and supportive nonpharmacological interventions [45].

\section{Individual Predisposition to NAS}

A question which has not been resolved despite numerous hypotheses is why some neonates will develop symptoms of neonatal abstinence syndrome, and others will not. The 
majority of studies that have examined the association between maternal maintenance dose and NAS have found no association $[21,23,27,46-50]$. A most recent review and meta-analysis of 67 studies on maternal methadone dose and NAS, and another encompassing 10 studies with various medications, support prior findings, also not reporting any correlation $[51,52]$. Factors that do have an impact on NAS and neonatal outcomes are concomitant consumption of opioids, cocaine, or other substances. In particular, benzodiazepine consumption has been associated with prolonged neonatal abstinence syndromes [53]. Another factor, which has been shown to play an important role during pregnancy, is the use of nicotine, as over $90 \%$ of opioid-dependent pregnant women are strongly dependent on nicotine [35, 54]. The prescription use of SSRIs and other psychotropic medications also has a negative impact on NAS [55]. The role of neonatal gender in NAS occurrence has been addressed in two prior studies which found inconclusive results. One study of a population of 64 neonates exposed to methadone found that male neonates exhibited a higher NAS intensity in the first four days postpartum, however, no sex-specific differences in rates of NAS treatment were found [55]. The second study reported no significant sex-related differences in a retrospective chart review of 308 methadone-exposed neonates [56].

Though some factors have been determined that can be seen as predictors of NAS, a lot of questions around this topic remain unresolved. There is a good chance that answers may actually rather be found on a more complex level such as biochemical processes in the placenta. Genetic variations of certain placental transporter genes could explain levels of maternal opioids in the fetal circulation during pregnancy, which in turn could explain severity and incidence of NAS $[57,58]$. However, further research is needed to clarify these findings, and it is also questionable how such genetic findings can contribute to therapeutic options.

\section{Breastfeeding and Maintenance Treatment}

Breastfeeding under oral opioid agonist treatment is recommendable for women if they are not comorbidly suffering from active forms of infectious disease such as hepatitis C with high blood viral loads; HIV is a definite contraindication. For methadone, breastfeeding can reduce the severity and duration of NAS and delay the onset of symptoms [59-61]. One reason for this can be the comfort obtained through mother/child bonding, another, the oral bioavailability of methadone. As a result of breast feeding under methadone maintenance, the need for medical treatment of NAS may be decreased [61]. If women want to breastfeed and no contraindication such as either infectious disease or continued illicit drug use exists, physicians should support their needs [62-64]. The safety of buprenorphine in breastfeeding has not been well-investigated. So far, data available show low concentrations in breast milk [65] so that a similar recommendation might be valid as for methadone. Nonetheless, though findings so far are supportive, they are restricted by shorter periods of observation and smaller numbers of investigated cases [66].

\section{Conclusion}

Opioid-dependent pregnant women are a highly vulnerable group of patients who frequently have unplanned pregnancy [7] and are at risk of unfavorable outcome and perinatal complications. They often suffer comorbid psychiatric disorders that need to be recognized and treated adequately in order to avoid complications during pregnancy and ensure a chance for healthy mother-child interaction. The majority of women benefits most from opioid agonist maintenance therapy with a long-acting synthetic opioid such as methadone or buprenorphine. The management of pain during delivery and thereafter is often challenging due to opioid tolerance and heightened pain sensitivity. Opioid-dependent pregnant women are in need of early and closely monitored treatment in a multiprofessional team approach including social workers, nurses, psychologists, psychiatrists, gynecologists, anesthesiologists, and pediatricians. The resolution of financial, legal, and housing issues, and the psychosocial support provided through treatment have a significant effect on optimizing pregnancy outcomes.

\section{References}

[1] Substance Abuse and Mental Health Services Administration, Results from the 2001 National Household Survey on Drug Abuse: Volume I. Summary of National Findings (Office of Applied Studies, NHSDA Series H-17, DHHS Publication No. SMA 02-3758), vol. 1, Substance Abuse and Mental Health Services Administration, Rockville, MD, USA, 2002.

[2] Substance Abuse and Mental Health Services Administration, Results from the 2008 National Household Survey on Drug Abuse: Volume I. Summary of National Findings (Office of Applied Studies, NHSDA Series H-17, DHHS Publication No. SMA 02-3758), Substance Abuse and Mental Health Services Administration, Rockville, MD, USA, 2009.

[3] I. J. Chasnoff, H. J. Landress, and M. E. Barrett, "The prevalence of illicit-drug or alcohol use during pregnancy and discrepancies in mandatory reporting in Pinellas County, Florida," New England Journal of Medicine, vol. 322, no. 17, pp. 1202-1206, 1990.

[4] B. Fischer, J. Rehm, M. Kirst et al., "Heroin-assisted treatment as a response to the public health problem of opiate dependence," European Journal of Public Health, vol. 12, no. 3, pp. 228-234, 2002.

[5] W. van den Brink, M. Goppel, and J. M. Van Ree, "Management of opioid dependence," Current Opinion in Psychiatry, vol. 16, no. 3, pp. 297-304, 2003.

[6] M. J. Kreek, J. Schluger, L. Borg, M. Gunduz, and A. Ho, "Dynorphin A1-13 causes elevation of serum levels of prolactin through an opioid receptor mechanism in humans: gender differences and implications for modulation of dopaminergic tone in the treatment of addictions," Journal of Pharmacology and Experimental Therapeutics, vol. 288, no. 1, pp. 260-269, 1999.

[7] S. H. Heil, H. E. Jones, A. Arria et al., "Unintended pregnancy in opioid-abusing women," Journal of Substance Abuse Treatment, vol. 40, no. 2, pp. 199-202, 2011. 
[8] B. C. Moore, C. J. Easton, and T. J. McMahon, "Drug abuse and intimate partner violence: a comparative study of opioiddependent fathers," American Journal of Orthopsychiatry, vol. 81, no. 2, pp. 218-227, 2011.

[9] A. Unger, E. Jung, B. Winklbaur, and G. Fischer, "Gender issues in the pharmacotherapy of opioid-addicted women: buprenorphine," Journal of Addictive Diseases, vol. 29, no. 2, pp. 217-230, 2010.

[10] H. E. Fitzsimons, M. Tuten, V. Vaidya, and H. E. Jones, "Mood disorders affect drug treatment success of drug-dependent pregnant women," Journal of Substance Abuse Treatment, vol. 32, no. 1, pp. 19-25, 2007.

[11] P. R. Martin, A. M. Arria, G. Fischer et al., "Psychopharmacologic management of opioid-dependent women during pregnancy," American Journal on Addictions, vol. 18, no. 2, pp. 148-156, 2009.

[12] S. Sterling and C. Weisner, "Chemical dependency and psychiatric services for adolescents in private managed care: implications for outcomes," Alcoholism: Clinical and Experimental Research, vol. 29, no. 5, pp. 801-809, 2005.

[13] S. Hoffman and M. C. Hatch, "Depressive symptomatology during pregnancy: evidence for an association with decreased fetal growth in pregnancies of lower social class women," Health Psychology, vol. 19, no. 6, pp. 535-543, 2000.

[14] J. Dayan, C. Creveuil, M. Herlicoviez et al., "Role of anxiety and depression in the onset of spontaneous preterm labor," American Journal of Epidemiology, vol. 155, no. 4, pp. 293-301, 2002.

[15] S. T. Orr, S. A. James, and C. B. Prince, "Maternal prenatal depressive symptoms and spontaneous preterm births among African-American women in Baltimore, Maryland," American Journal of Epidemiology, vol. 156, no. 9, pp. 797-802, 2002.

[16] C. Hornstein, P. Trautmann-Villalba, E. Hohm, E. Rave, S. Wortmann-Fleischer, and M. Schwarz, "Maternal bond and mother-child interaction in severe postpartum psychiatric disorders: is there a link?" Archives of Women's Mental Health, vol. 9, no. 5, pp. 279-284, 2006.

[17] M. P. Austin, "To treat or not to treat: maternal depression, SSRI use in pregnancy and adverse neonatal effects," Psychological Medicine, vol. 36, no. 12, pp. 1663-1670, 2006.

[18] J. S. Dashe, G. L. Jackson, D. A. Olscher, E. H. Zane, and G. D. Wendel, "Opioid detoxification in pregnancy," Obstetrics and Gynecology, vol. 92, no. 5, pp. 854-858, 1998.

[19] H. E. Jones, K. E. O'Grady, D. Malfi, and M. Tuten, "Methadone maintenance vs. methadone taper during pregnancy: maternal and neonatal outcomes," American Journal on Addictions, vol. 17, no. 5, pp. 372-386, 2008.

[20] B. Winklbaur, N. Kopf, N. Ebner, E. Jung, K. Thau, and G. Fischer, "Treating pregnant women dependent on opioids is not the same as treating pregnancy and opioid dependence: a knowledge synthesis for better treatment for women and neonates," Addiction, vol. 103, no. 9, pp. 1429-1440, 2008.

[21] C. Lejeune, L. Simmat-Durand, L. Gourarier, and S. Aubisson, "Prospective multicenter observational study of 260 infants born to 259 opiate-dependent mothers on methadone or high-dose buprenophine substitution," Drug and Alcohol Dependence, vol. 82, no. 3, pp. 250-257, 2006.

[22] G. Fischer, R. E. Johnson, H. Eder et al., "Treatment of opioiddependent pregnant women with buprenorphine," Addiction, vol. 95, no. 2, pp. 239-244, 2000.

[23] G. Fischer, R. Ortner, K. Rohrmeister et al., "Methadone versus buprenorphine in pregnant addicts: a double-blind, doubledummy comparison study," Addiction, vol. 101, no. 2, pp. 275281, 2006.
[24] H. E. Jones, R. E. Johnson, D. R. Jasinski et al., "Buprenorphine versus methadone in the treatment of pregnant opioiddependent patients: effects on the neonatal abstinence syndrome," Drug and Alcohol Dependence, vol. 79, no. 1, pp. 1-10, 2005.

[25] L. P. Finnegan, R. E. Kron, J. F. Connaughton, and J. P. Emich, "Assessment and treatment of abstinence in the infant of the drug dependent mother," International Journal of Clinical Pharmacology Therapy and Toxicology, vol. 12, no. 1-2, pp. 1932, 1975.

[26] S. R. Kandall, T. M. Doberczak, M. Jantunen, and J. Stein, “The methadone-maintained pregnancy," Clinics in Perinatology, vol. 26, no. 1, pp. 173-183, 1999.

[27] S. D. Schindler, H. Eder, R. Ortner, K. Rohrmeister, M. Langer, and G. Fischer, "Neonatal outcome following buprenorphine maintenance during conception and throughout pregnancy," Addiction, vol. 98, no. 1, pp. 103-110, 2003.

[28] H. E. Jones, K. Kaltenbach, S. H. Heil et al., "Neonatal abstinence syndrome after methadone or buprenorphine exposure," New England Journal of Medicine, vol. 363, no. 24, pp. 2320-2331, 2010.

[29] J. Drozdick, V. Berghella, M. Hill, and K. Kaltenbach, "Methadone trough levels in pregnancy," American Journal of Obstetrics and Gynecology, vol. 187, no. 5, pp. 1184-1188, 2002.

[30] S. M. Pond, M. J. Kreek, and T. G. Tong, "Altered methadone pharmacokinetics in methadone-maintained pregnant women," Journal of Pharmacology and Experimental Therapeutics, vol. 233, no. 1, pp. 1-6, 1985.

[31] E. Peles, S. Schreiber, M. Bloch, S. Dollberg, and M. Adelson, "Duration of Methadone Maintenance Treatment During Pregnancy and Pregnancy Outcome Parameters in Women With Opiate Addiction," Journal of Addiction Medicine. In press.

[32] A. Höflich, M. Langer, R. Jagsch et al., "Peripartum pain management in opioid dependent women," European Journal of Pain. In press.

[33] F. M. Creekmore, R. A. Lugo, and K. J. Weiland, "Postoperative opiate analgesia requirements of smokers and nonsmokers," Annals of Pharmacotherapy, vol. 38, no. 6, pp. 949-953, 2004.

[34] W. M. Hooten, C. O. Townsend, B. K. Bruce, and D. O. Warner, "The effects of smoking status on opioid tapering among patients with chronic pain," Anesthesia and Analgesia, vol. 108, no. 1, pp. 308-315, 2009.

[35] B. Winklbaur, A. Baewert, R. Jagsch et al., "Association between prenatal tobacco exposure and outcome of neonates born to opioid-maintained mothers," European Addiction Research, vol. 15, no. 3, pp. 150-156, 2009.

[36] M. R. Zarrindast, M. R. Khoshayand, and B. Shafaghi, "The development of cross-tolerance between morphine and nicotine in mice," European Neuropsychopharmacology, vol. 9, no. 3, pp. 227-233, 1999.

[37] I. R. Carroll, M. S. Angst, and J. D. Clark, "Management of perioperative pain in patients chronically consuming opioids," Regional Anesthesia and Pain Medicine, vol. 29, no. 6, pp. 576591, 2004.

[38] V. Mehta and R. M. Langford, "Acute pain management for opioid dependent patients," Anaesthesia, vol. 61, no. 3, pp. 269-276, 2006.

[39] H. E. Jones, K. O’Grady, J. Dahne et al., "Management of acute postpartum pain in patients maintained on methadone or buprenorphine during pregnancy," American Journal of Drug and Alcohol Abuse, vol. 35, no. 3, pp. 151-156, 2009. 
[40] M. E. Ostensen and J. F. Skomsvoll, "Anti-inflammatory pharmacotherapy during pregnancy," Expert Opinion on Pharmacotherapy, vol. 5, no. 3, pp. 571-580, 2004.

[41] D. A. Osborn, H. Jeffery, and M. J. Cole, "Opiate treatment for opiate withdrawal in newborn infants," Cochrane Database of Systematic Reviews, no. 10, Article ID CDDOO2059, 2010.

[42] L. P. Finnegan, J. F. Connaughton Jr., R. E. Kron, and J. P. Emich, "Neonatal abstinence syndrome: assessment and management," Addictive Diseases, vol. 2, no. 1-2, pp. 141-158, 1975.

[43] N. Ebner, K. Rohrmeister, B. Winklbaur et al., "Management of neonatal abstinence syndrome in neonates born to opioid maintained women," Drug and Alcohol Dependence, vol. 87, no. 2-3, pp. 131-138, 2007.

[44] R. Liu, T. Björkman, C. Stewart, and R. Nanan, "Pharmacological treatment of neonatal opiate withdrawal: between the devil and the deep blue sea," International Journal of Pediatrics, vol. 2011, Article ID 935631, 5 pages, 2011.

[45] M. Velez and L. M. Jansson, "The opioid dependent mother and newborn dyad: nonpharmacologic care," Journal of Addiction Medicine, vol. 2, no. 3, pp. 113-120, 2008.

[46] J. Kakko, M. Heilig, and I. Sarman, "Buprenorphine and methadone treatment of opiate dependence during pregnancy: comparison of fetal growth and neonatal outcomes in two consecutive case series," Drug and Alcohol Dependence, vol. 96, no. 1-2, pp. 69-78, 2008.

[47] A. Unger, R. Jagsch, H. Jones et al., "Randomized controlled trials in pregnancy: scientific and ethical aspects. Exposure to different opioid medications during pregnancy in an intraindividual comparison," Addiction, vol. 106, no. 7, pp. 13551362, 2011.

[48] B. Bakstad, M. Sarfi, G. K. Welle-Strand, and E. Ravndal, "Opioid maintenance treatment during pregnancy: occurrence and severity of neonatal abstinence syndrome," European Addiction Research, vol. 15, no. 3, pp. 128-134, 2009.

[49] H. Kahila, T. Saisto, S. Kivitie-Kallio, M. Haukkamaa, and E. Halmesmäki, "A prospective study on buprenorphine use during pregnancy: effects on maternal and neonatal outcome," Acta Obstetricia et Gynecologica Scandinavica, vol. 86, no. 2, pp. 185-190, 2007.

[50] V. Berghella, P. J. Lim, M. K. Hill, J. Cherpes, J. Chennat, and K. Kaltenbach, "Maternal methadone dose and neonatal withdrawal," American journal of obstetrics and gynecology, vol. 189, no. 2, pp. 312-317, 2003.

[51] B. J. Cleary, J. Donnelly, J. Strawbridge et al., "Methadone dose and neonatal abstinence syndrome-systematic review and meta-analysis," Addiction, vol. 105, no. 12, pp. 2071-2084, 2010.

[52] D. Thajam, D. E. Atkinson, C. P. Sibley, and T. Lavender, "Is neonatal abstinence syndrome related to the amount of opiate used?" Journal of Obstetric, Gynecologic, and Neonatal Nursing, vol. 39, no. 5, pp. 503-509, 2010.

[53] E. M. Wachman, P. K. Newby, J. Vreelang et al., "The relationship between maternal opioid agonists and psychiatric medications on length of hospitalization for neonatal abstinence syndrome," Journal of Addiction Medicine, vol. 5, no. 4, pp. 293-299, 2011.

[54] R. E. Choo, M. A. Huestis, J. R. Schroeder, A. S. Shin, and H. E. Jones, "Neonatal abstinence syndrome in methadone-exposed infants is altered by level of prenatal tobacco exposure," Drug and Alcohol Dependence, vol. 75, no. 3, pp. 253-260, 2004.

[55] L. M. Jansson, J. A. DiPietro, A. Elko, and M. Velez, "Infant autonomic functioning and neonatal abstinence syndrome,"
Drug and Alcohol Dependence, vol. 109, no. 1-3, pp. 198-204, 2010.

[56] A. Holbrook and K. Kaltenbach, "Gender and NAS: does sex matter?” Drug and Alcohol Dependence, vol. 112, no. 1-2, pp. 156-159, 2010.

[57] I. Nekhayeva, T. Nanovskaya, G. Hankins, and M. Ahmed, "Role of human placental efflux transporter P-glycoprotein in the transfer of buprenorphine, levo- $\alpha$-acetylmethadol, and paclitaxel," American Journal of Perinatology, vol. 23, no. 7, pp. 423-430, 2006.

[58] T. Nanovskaya, I. Nekhayeva, N. Karunaratne, K. Audus, G. D. V. Hankins, and M. S. Ahmed, "Role of P-glycoprotein in transplacental transfer of methadone," Biochemical Pharmacology, vol. 69, no. 12, pp. 1869-1878, 2005.

[59] C. Dryden, D. Young, M. Hepburn, and H. MacTier, "Maternal methadone use in pregnancy: factors associated with the development of neonatal abstinence syndrome and implications for healthcare resources," An International Journal of Obstetrics and Gynaecology, vol. 116, no. 5, pp. 665-671, 2009.

[60] A. J. Liu and R. Nanan, "Methadone maintenance and breastfeeding in the neonatal period," Pediatrics, vol. 121, no. 4, p. 869, 2008.

[61] M. E. Abdel-Latif, J. Pinner, S. Clews, F. Cooke, K. Lui, and J. Oei, "Effects of breast milk on the severity and outcome of neonatal abstinence syndrome among infants of drugdependent mothers," Pediatrics, vol. 117, no. 6, pp. e1163e1169, 2006.

[62] The American Academy of Physicians, "Breastfeeding and infant nutrition," in 1994-1995 Compendium of AAFP Positions on Selected Health Issues, The American Academy of Family Physicians, Kansas City, Mo, USA, 1996.

[63] L. M. Jansson, R. Choo, M. L. Velez et al., "Methadone maintenance and breastfeeding in the neonatal period," Pediatrics, vol. 121, no. 1, pp. 106-114, 2008.

[64] R. M. Ward, B. A. Bates, W. E. Benitz, D. J. Burchfield, J. C. Ring, and R. P. Walls, "The transfer of drugs and other chemicals into human milk," Pediatrics, vol. 108, no. 3, pp. 776-789, 2001.

[65] S. Lindemalm, P. Nydert, J. O. Svensson, L. Stahle, and I. Sarman, "Transfer of buprenorphine into breast milk and calculation of infant drug dose," Journal of Human Lactation, vol. 25, no. 2, pp. 199-205, 2009.

[66] D. Grimm, E. Pauly, J. Pöschl, O. Linderkamp, and G. Skopp, "Buprenorphine and norbuprenorphine concentrations in human breast milk samples determined by liquid chromatography-tandem mass spectrometry," Therapeutic Drug Monitoring, vol. 27, no. 4, pp. 526-530, 2005. 


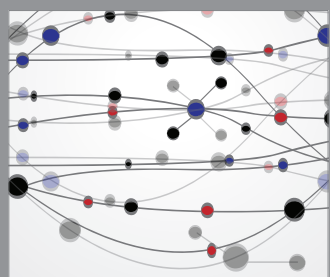

The Scientific World Journal
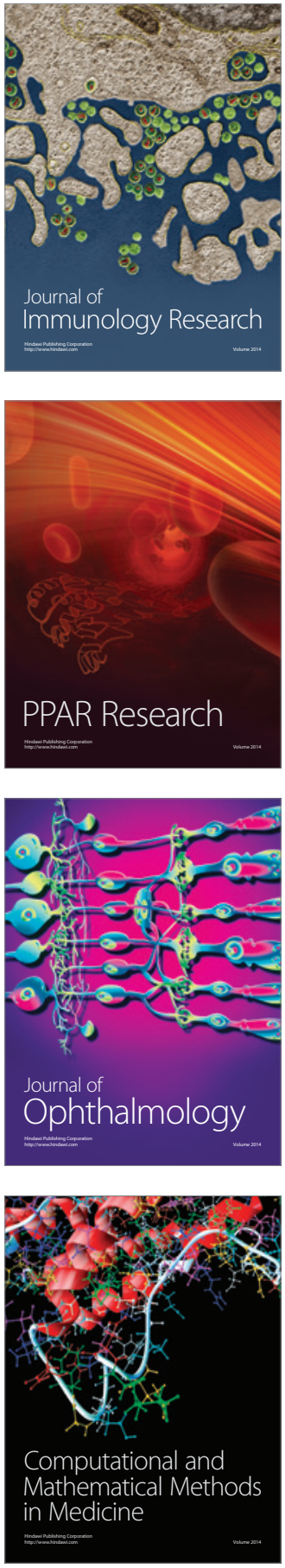

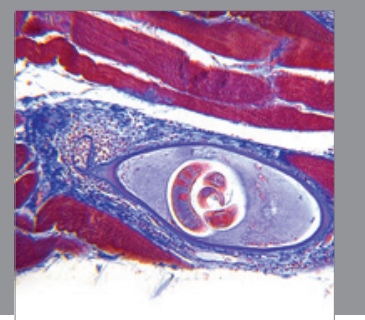

Gastroenterology

Research and Practice
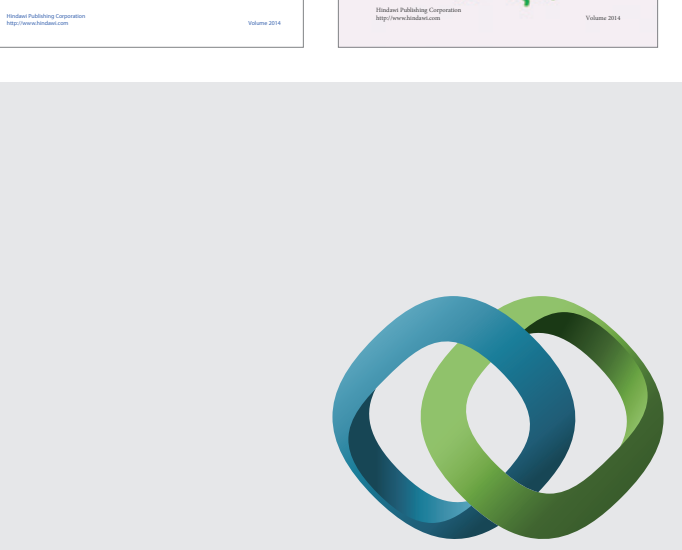

\section{Hindawi}

Submit your manuscripts at

http://www.hindawi.com
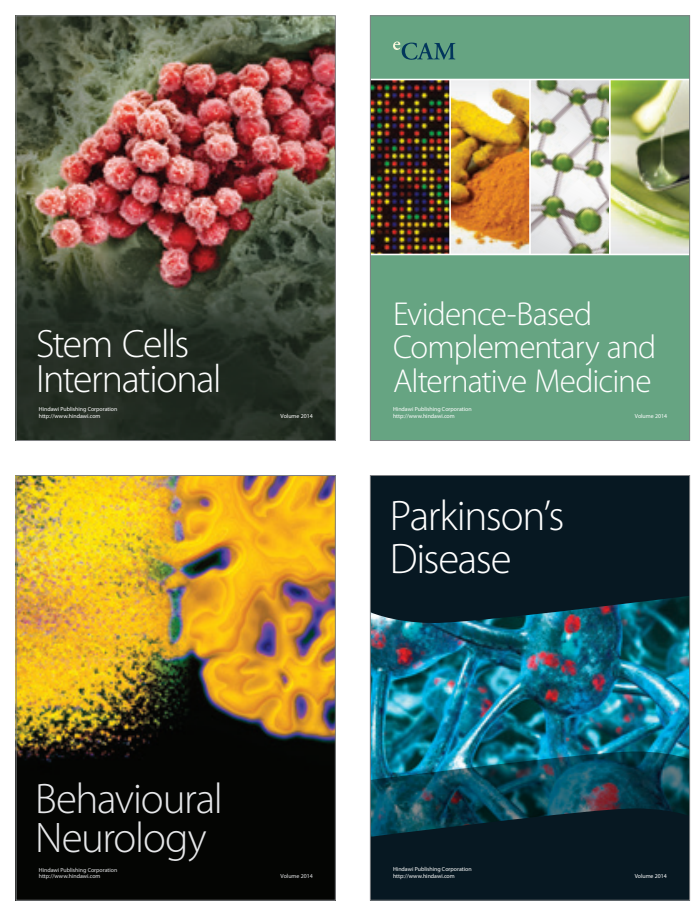

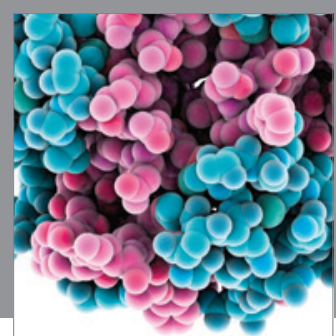

Journal of
Diabetes Research

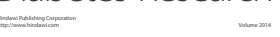

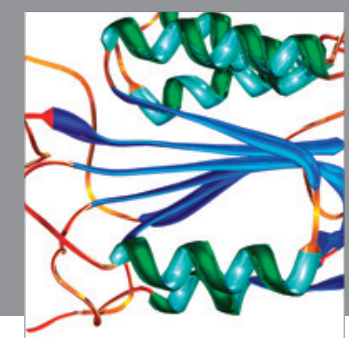

Disease Markers
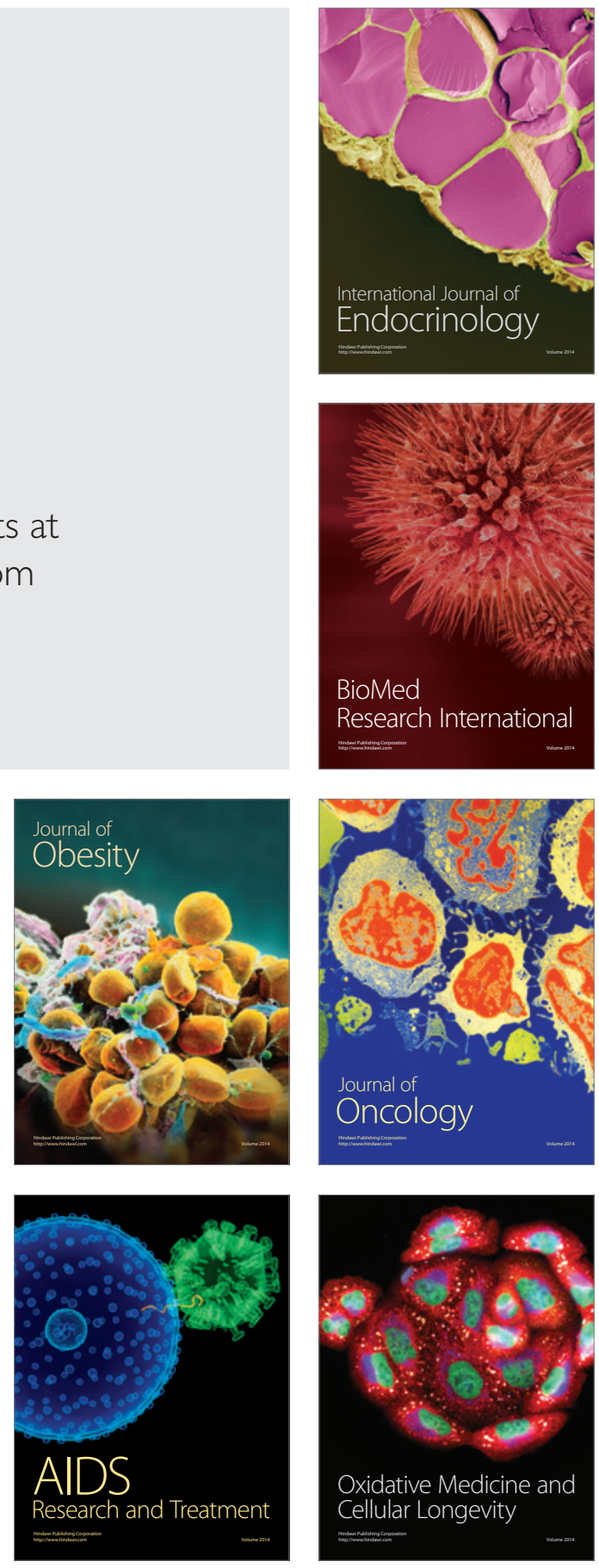